\title{
Erratum to: 'Clinical impact of PSMA PET in biochemically recurrent prostate cancer; a review of the literature'
}

\author{
Maurits Wondergem · Friso M. van der Zant · Wouter A. M. Broos · Remco J. J. Knol
}

Published online: 2 September 2020

(c) The Author(s) 2020

\section{Erratum to:}

Tijdschr Urol 2020

https://doi.org/10.1007/s13629-020-00296-6

In the article 'Clinical impact of PSMA PET in biochemically recurrent prostate cancer; a review of the literature' (Tijdschrift voor Urologie, October 2020), the column headings of Tab. 3 are missing. The complete table is presented below.

Open Access This article is distributed under the terms of the Creative Commons Attribution 4.0 International License (http://creativecommons.org/licenses/by/4.0/), which permits unrestricted use, distribution, and reproduction in any medium, provided you give appropriate credit to the original author(s) and the source, provide a link to the Creative Commons license, and indicate if changes were made.

Maurits Wondergem, MD, PhD, nuclear medicine physician

Friso M. van der Zant, MD, PhD, nuclear medicine physician

Wouter A.M. Broos, MD, nuclear medicine physician

Remco J.J. Knol, MD, PhD, nuclear medicine physician

\footnotetext{
The online version of the original article can be found under https://doi.org/10.1007/s13629-020-00296-6.

M. Wondergem, MD, PhD ( $₫) \cdot$ F. M. van der Zant, MD,

$\mathrm{PhD}$. W. A. M. Broos, MD · R. J. J. Knol, MD, PhD

Department of Nuclear Medicine, Noordwest

Ziekenhuisgroep, Alkmaar, The Netherlands

m.wondergem@nwz.nl
} 
离

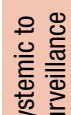

के ڤँ

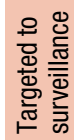

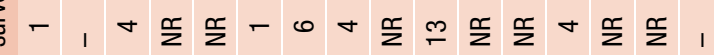

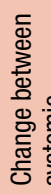

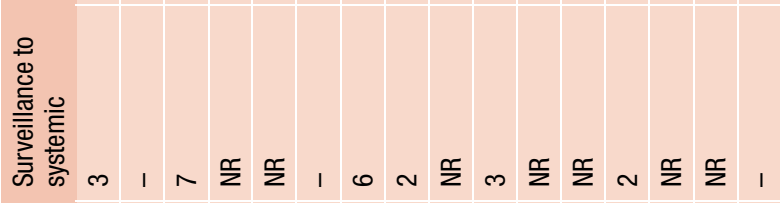

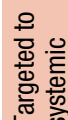

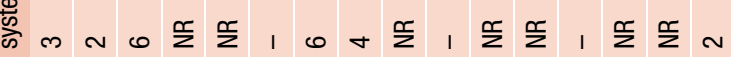

离

范

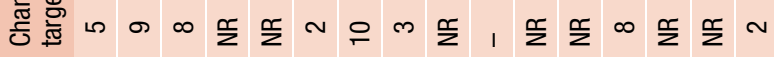

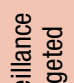

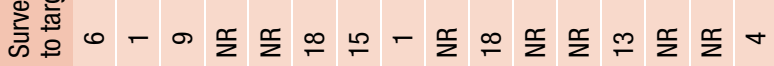

웅

苮

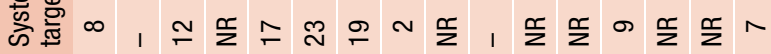

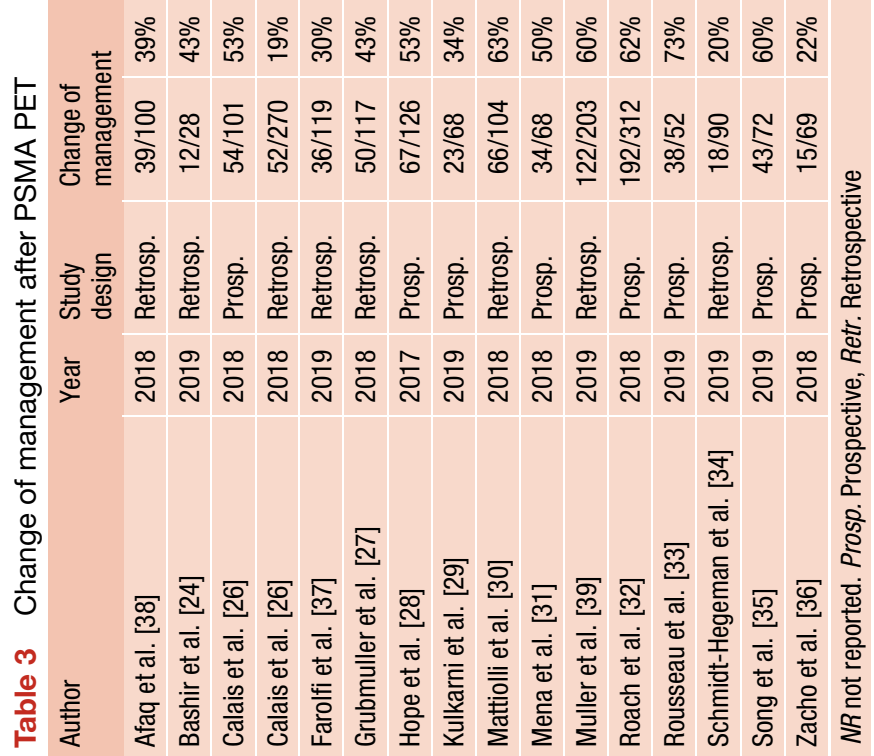

